\title{
Ion and neutral temperature distributions in the E-region observed by the EISCAT Tromsø and Svalbard radars
}

\author{
S. Maeda ${ }^{1}$, S. Nozawa ${ }^{2}$, M. Sugino ${ }^{2}$, H. Fujiwara ${ }^{3}$, and M. Suzuki ${ }^{3}$ \\ ${ }^{1}$ Faculty for the Study of Contemporary Society, Kyoto Women's University, Higashiyama-ku, Kyoto 605-8501, Japan \\ ${ }^{2}$ Solar-Terrestrial Environment Laboratory, Nagoya University, Chikusa-ku, Nagoya 464-8601, Japan \\ ${ }^{3}$ Department of Geophysics, Graduate School of Science, Tohoku University, Aoba-ku, Sendai 980-8578, Japan
}

Received: 9 October 2001 - Revised: 10 June 2002 - Accepted: 14 June 2002

\begin{abstract}
Simultaneous Common Program Two experiments by the EISCAT UHF radar at Troms $\varnothing$ and the EISCAT Svalbard radar at Longyearbyen from 00:00 to 15:00 UT on 22 September 1998 and 9 March 1999 have been utilized to investigate distributions of the ion and neutral temperatures in the E-region between 105 and $115 \mathrm{~km}$. During the experiments, soft particle precipitations in the dayside cusp were observed over the Svalbard radar site by the Defense Meteorological Satellite Program (DMSP) F11 satellite. It is found that the dayside electric field in the regions of the lowlatitude boundary of the polar cap and the cusp was greater and more variable than that in the auroral region. The ion temperature, parallel to the geomagnetic field at Longyearbyen, was higher than that at Troms $\varnothing$ during the daytime from 06:00 to 12:00 UT. The steady-state ion energy equation has been applied to derive neutral temperature under the assumption of no significant heat transport and viscous heating. The estimated neutral temperature at Longyearbyen was also higher than that at Troms $\emptyset$. The ion and neutral energy budget was discussed in terms of the ion frictional heating and the Joule heating. The results indicate two possibilities: either the neutral temperature was high in the low latitude boundary of the polar cap and the cusp, or the heat transport by the polar cap neutral winds toward the dayside sector was significant.
\end{abstract}

Key words. Ionosphere (auroral ionosphere; ionosphereatmosphere interactions; polar ionosphere)

\section{Introduction}

The dynamics and thermodynamics of the F-region polar thermosphere were extensively explored in 1980s based upon the various observations made from the Dynamics Explorer 2 satellite (Killeen et al., 1984). One of the most outstanding features disclosed was that the geomagnetic polar cap and the dayside cusp were hotter than the auroral region (Hays et

Correspondence to: S. Maeda (smaeda@kyoto-wu.ac.jp) al., 1984). This was speculated to be a direct consequence of Joule and soft particle heating in the polar cusp and thermal advection by the polar cap neutral winds.

To interpret the diurnal variations of the F-region neutral temperature observed by the Fabry-Perot interferometer located at Thule, Greenland $\left(\Lambda=86^{\circ}\right)$, McCormac et al. (1988) performed numerical simulations by using the NCAR thermospheric general circulation model (TGCM). They found that the neutral temperature maximum near the magnetic local noon was primarily due to transport of heat to the polar cap by parcels heated by auroral, Joule and cusp sources.

The high-latitude ion temperature depends on the magnetospheric energy input. In the presence of strong dc electric fields, a relative velocity between ions and neutrals results in an enhancement in the ion temperature through frictional contact with the neutral gases, particularly in the Fregion, because the significant relative velocity between ions and neutrals exists due to the small collision frequency between them. A statistical study of the ion frictional heating, based on the F-region field-parallel ion temperature measured by the European Incoherent Scatter (EISCAT) UHF radar (Folkestad et al., 1983), showed that the ion frictional heating at Troms $\varnothing$ (geomagnetic coordinates $66.54^{\circ} \mathrm{N}$, $103.44^{\circ} \mathrm{E}$ ) was observed principally during nights and little heating occurred on the dayside (Davies et al., 1997). The maximum of the ion temperature during the night was explained from the location of the radar relative to the largescale ion convection pattern. Since both the ion frictional heating rate and neutral heating rate due to the Joule dissipation of electric currents are proportional to the square of the relative velocity between ions and neutrals (Banks, 1980; St.-Maurice et al., 1999), it is inferred that the neutral heating at latitudes lower than about $70^{\circ}$ occurs mainly on the night side, in contrast to the heating within the polar cap.

The E-region neutral temperature is highly dependent on Joule and particle heating. Brekke and Rino (1978) studied energy transfer between the ionosphere and the thermosphere by using the incoherent scatter (IS) radar at Chatanika, 
Alaska (geographic coordinate $65.1^{\circ} \mathrm{N}, 147.4^{\circ} \mathrm{W}$ ). Since then, numerous works on the Joule heating rate in the lower thermosphere have been made from the point of view of the magnetosphere-ionosphere-thermosphere energy coupling (Lu et al., 1995; Fujii et al., 1999, 2000) and of the neutral wind effects (Thayer and Vickrey, 1992; Thayer et al., 1995; Fujii et al., 1998; Thayer, 1998). Some of these works are based on the IS radar observations in the auroral zone, i.e. the EISCAT UHF radar at Troms $\varnothing$ (Fujii et al., 1998, 2000) and some are in the polar cap, i.e. the Sondrestrom radar (Thayer, 1998). However, there has been no direct comparison between the Joule heating rates in the auroral oval and the polar cap based on simultaneous observations. Furthermore, it is not yet disclosed whether the E-region polar cap is hotter than the auroral region, particularly on the dayside.

The dayside E-region neutral dynamics during a magnetically quiet period was studied using the EISCAT UHF radar at Troms $\varnothing$ in terms of a momentum balance among the various forcings such as the Coriolis force, the pressure gradient force, the viscous force, the tidal force, and the electromagnetic force (Maeda et al., 1999). In a certain height range between 106 and $110 \mathrm{~km}$, the Coriolis force was balanced with the southward pressure gradient force, which corresponded to the northward temperature gradient. In other words, the neutral temperature became higher to the north. Since the momentum balance is maintained locally, the northward temperature gradient derived only from the EISCAT UHF radar data does not necessarily mean a higher temperature in the polar cap than in the auroral region.

The EISCAT Svalbard radar at Longyearbyen (geomagnetic coordinates $75.12^{\circ} \mathrm{N}, 113.00^{\circ} \mathrm{E}$ ) has been operated since 1996, (Wannberg et al., 1997). From statistical patterns of the large-scale ion convection derived from the Defense Meteorological Satellite Program (DMSP) ion drift data (Rich and Hairston, 1994), it is inferred that, on the dayside, Longyearbyen is located beneath the cusp and the low-latitude boundary of the polar cap and Troms $\varnothing$ in the auroral and/or sub-auroral region. It is quite feasible to use the data obtained simultaneously with the two radars for a study of dynamics and thermodynamics over the polar cap and the auroral region.

The purpose of this paper is to investigate ion and neutral temperature distributions and the related energy budget over the polar cap, the cusp, the low latitude boundary of the polar cap and the auroral zone by using the data set obtained from simultaneous measurements by the EISCAT UHF radar at Troms $\varnothing$ (called the Troms $\varnothing$ radar, hereafter) and the EISCAT Svalbard radar at Longyearbyen (called the Svalbard radar, hereafter). In this work, we used the data obtained by the monostatic beamswinging method of the Common Program Two (CP-2) mode: the Troms $\emptyset$ radar with CP-2 version $\mathrm{E}$ and the Svalbard radar with CP-2 version L. The alternating pulse code was used except for the F-region ion velocity that was measured with the long pulses. In the CP-2 mode, the line of sight of the antenna is pointed into four consecutive positions with a dwell time of about $60 \mathrm{~s}$ and $110 \mathrm{~s}$ in each position, resulting in a full cycle time of the antenna of $6 \mathrm{~min}$ and $8 \mathrm{~min}$
Table 1. Antenna positions

\begin{tabular}{lcccc}
\hline radar & \multicolumn{2}{c}{ Troms $\emptyset$ radar } & \multicolumn{2}{c}{ Svalbard radar } \\
\hline experiment & \multicolumn{2}{c}{ CP-2-E } & \multicolumn{2}{c}{ CP-2-L } \\
\hline beam & Azimuth $\left({ }^{\circ}\right)$ & Elevation $\left({ }^{\circ}\right)$ & Azimuth $\left({ }^{\circ}\right)$ & Elevation $\left({ }^{\circ}\right)$ \\
Field aligned & 182.6 & 77.5 & 180.3 & 81.6 \\
Vertical & 180.0 & 89.9 & 180.0 & 90.0 \\
East & 166.5 & 62.9 & 171.6 & 63.2 \\
Eastmost & 133.3 & 60.4 & 144.4 & 66.6 \\
\hline
\end{tabular}

for the Troms $\varnothing$ radar and the Svalbard radar, respectively. The antenna positions of the two radars are listed in Table 1. The altitude resolution is about $3 \mathrm{~km}$.

In Sect. 2, the ion and neutral energy conservation equations are introduced. The methods of data analysis are described in Sect. 3. Section 4 summarizes conditions of the interplanetary magnetic field and geomagnetic activity. In Sect. 5, the ion and neutral temperatures and related energy budgets are discussed. Section 6 summarizes our results.

\section{Ion and neutral energy equations}

The ion energy equation is written as (Banks and Kockarts, 1973; Schunk, 1977; Banks, 1980; St.-Maurice and Hanson, 1982; Schunk and Nagy, 2000)

$$
\begin{gathered}
\frac{D}{D t}\left(\frac{3}{2} p_{i}\right)+\frac{5}{2} p_{i}\left(\nabla \cdot \boldsymbol{V}_{i}\right)+\nabla \cdot \boldsymbol{q}_{i}+\boldsymbol{\tau}_{i}: \nabla \boldsymbol{V}_{i} \\
=\frac{n_{i} m_{i} v_{i n}}{m_{i}+m_{n}}\left[3 \kappa_{B}\left(T_{n}-T_{i}\right)+m_{n}\left(\boldsymbol{V}_{i}-\boldsymbol{V}_{n}\right)^{2}\right] \\
\quad+\frac{n_{i} m_{i} v_{i e}}{m_{i}+m_{e}}\left[3 \kappa_{B}\left(T_{e}-T_{i}\right)+m_{e}\left(\boldsymbol{V}_{i}-\boldsymbol{V}_{e}\right)^{2}\right]
\end{gathered}
$$

where $p_{i}$ is the ion pressure, $\boldsymbol{\tau}_{i}$ is the ion stress tensor, $\boldsymbol{V}_{i}$, $\boldsymbol{V}_{n}$, and $\boldsymbol{V}_{e}$ are the ion, neutral, and electron velocities, respectively; $T_{i}, T_{n}$, and $T_{e}$ are the ion, neutral, and electron temperatures, respectively; $m_{i}, m_{n}$, and $m_{e}$ are the ion, neutral, and electron masses, respectively; $n_{i}$ is the ion number density, $\kappa_{B}$ is the Boltzmann's constant, $\boldsymbol{q}_{i}$ is the ion heat flux vector and $v_{i n}$ and $v_{i e}$ are the ion-neutral and ion-electron momentum transfer collision frequencies, respectively. The term $\boldsymbol{\tau}_{i}: \boldsymbol{\nabla} \boldsymbol{V}_{i}$ expresses the viscous heating. It should be noted that Eq. (1) is applied to a single neutral species and not summed over several neutral species, unlike those of Schunk (1977), Banks (1980), and St.-Maurice and Hanson (1982). Here we have assumed that one neutral species having a mass equal to the mean molecular mass dominates the atmospheric composition.

St.-Maurice and Hanson (1982) discussed the terms on the left-hand side of Eq. (1); these are negligibly small in the F-region, although this is not necessarily so in the E-region. The terms on the left-hand side were neglected in the present analysis for simplicity. The second part of the last term on the right-hand side of Eq. (1) describes the frictional heating 
between ions and electrons. In the E-region, there would be a large relative velocity between ions and electrons due to ion-neutral collisions. In this work, however, this term was neglected as the effects on the ion energy budget might be small owing to the small electron mass. It was also assumed that $m_{i}+m_{e}=m_{i}$ because of the small electron mass. Then the steady-state ion energy balance can be expressed as

$$
\begin{aligned}
T_{i} & =T_{n}+\frac{m_{n}}{3 \kappa_{B}}\left(\boldsymbol{V}_{i}-\boldsymbol{V}_{n}\right)^{2} \\
& +\frac{m_{i}+m_{n}}{m_{i}} \frac{v_{i e}}{v_{i n}}\left(T_{e}-T_{i}\right)
\end{aligned}
$$

The second term on the right-hand side of Eq. (2) represents the heating due to the friction between ions and neutrals, namely, 'ion frictional heating'. The heat exchange between ions and electrons, expressed by the last term on the right-hand side of Eq. (2), is usually neglected when the electric field is less than $20 \mathrm{mV} / \mathrm{m}$ (Williams et al., 1992; Davies and Robinson, 1997). The heat exchange between ions and electrons will be discussed in Sect. 5.1.

When a relative flow is high between ions and neutrals, the ion thermal velocity distribution may depart significantly from a Maxwellian form, resulting in an anisotropic distribution (St.-Maurice and Schunk, 1977; Lathuillere and Hubert, 1989; McCrea et al., 1993). Under such conditions, these ions can no longer be characterized by a single ion temperature, since the apparent width of the thermal velocity distribution depends on the direction from which it is observed. As a first approximation, St.-Maurice and Schunk (1977, 1979) showed that the ion velocity distribution function is represented by a bi-Maxwellian with two ion temperatures; parallel and perpendicular to the geomagnetic field. When the heat exchange between ions and electrons is negligibly small, the parallel temperature $T_{i \|}$ satisfies the following relationship with the neutral temperature:

$T_{i \|}=T_{n}+\beta_{\|} \frac{m_{n}}{2 \kappa_{B}}\left(\boldsymbol{V}_{i}-\boldsymbol{V}_{n}\right)^{2}$

where the parameter $\beta_{\|}$is the partition coefficient for the parallel ion temperature. The partition coefficient depends on a collision model, and has been extensively investigated mainly for the F-region (Winkler et al., 1992; McCrea et al., 1993; Balmforth et al., 1999; St.-Maurice et al., 1999). In addition to the anisotropic ion temperatures, non-Maxwellian line-of-sight ion velocity distributions during periods of high electric field have been discussed by using the Troms $\emptyset$ radar data (Lockwood et al., 1987; McCrea et al., 1993).

The energy budget of the neutral gases can be discussed by using the neutral energy equation (Banks and Kockarts, 1973; Schunk, 1977; Banks, 1980):

$$
\begin{aligned}
& \frac{D}{D t}\left(\frac{3}{2} p_{n}\right)+\frac{5}{2} p_{n}\left(\boldsymbol{\nabla} \cdot \boldsymbol{V}_{n}\right)+\nabla \cdot \boldsymbol{q}_{n}+\boldsymbol{\tau}_{n}: \nabla \boldsymbol{V}_{n} \\
& \quad=\frac{n_{n} m_{n} v_{n i}}{m_{n}+m_{i}}\left[3 \kappa_{B}\left(T_{i}-T_{n}\right)+m_{i}\left(\boldsymbol{V}_{n}-\boldsymbol{V}_{i}\right)^{2}\right] \\
& \quad+\frac{n_{n} m_{n} v_{n e}}{m_{n}+m_{e}}\left[3 \kappa_{B}\left(T_{e}-T_{n}\right)+m_{e}\left(\boldsymbol{V}_{n}-\boldsymbol{V}_{e}\right)^{2}\right]+Q-L
\end{aligned}
$$

where $p_{n}$ is the neutral pressure, $\boldsymbol{\tau}_{n}$ is the neutral stress tensor, $n_{n}$ is the neutral number density, $\boldsymbol{q}_{n}$ is the neutral heat flux vector, $Q$ and $L$ are the heat source such as a chemical heating and the sink including a radiative cooling, respectively; and $v_{n i}$ and $v_{n e}$ are the neutral-ion and neutralelectron momentum transfer collision frequencies, respectively. Here, no particular source and sink are considered. It is noted that the sum of the ion-neutral heat exchange plus the direct frictional heating of the neutral gases is what is referred to as the 'Joule heating rate' (Banks and Kockarts, 1973; St.-Maurice and Hanson, 1982):

$$
\begin{aligned}
& \frac{n_{n} m_{n} v_{n i}}{m_{n}+m_{i}}\left[3 \kappa_{B}\left(T_{i}-T_{n}\right)+m_{i}\left(\boldsymbol{V}_{n}-\boldsymbol{V}_{i}\right)^{2}\right] \\
& \quad=\sigma_{P}\left(\boldsymbol{E}+\boldsymbol{V}_{\boldsymbol{n}} \times \boldsymbol{B}\right)^{2}
\end{aligned}
$$

where $\boldsymbol{B}$ is the magnetic field, $\boldsymbol{E}$ is the electric field and $\sigma_{P}$ is the Pedersen conductivity. The second term on the right-hand side of Eq. (4) expresses electron contribution, which we did not discuss by assuming that it might be small compared with the Joule heating effect.

\section{Method of analysis}

As discussed in Sect. 2, the ion velocity distribution may not be represented by a Maxwellian under the presence of strong electric fields. As will be shown later, the electric field at Troms $\varnothing$ was mostly less than a few tens of $\mathrm{mV} / \mathrm{m}$. The ion temperature was isotropic and the parameter $\beta_{\|}=2 / 3$ in this case. On the other hand, the electric field at Longyearbyen was sometimes greater than $50 \mathrm{mV} / \mathrm{m}$, and an anisotropy in the ion temperature should be taken into account. Although there are not many experimental studies of non-Maxwellian ion velocity distributions in the altitude region below $130 \mathrm{~km}$ (Venkat Raman et al., 1981), there have been several approaches to estimate the temperature partition coefficient $\beta_{\|}$ for E- and F-regions. For polarization-type interactions, St.Maurice and Schunk (1977) obtained values of the coefficient: $\beta_{\|}=0.52$ for $m_{i} / m_{n}=2$, and $\beta_{\|}=0.59$ for $m_{i} / m_{n}=0.5$. Monte Carlo simulations by Winkler et al. (1992) provided values for the electric field of $50 \mathrm{mV} / \mathrm{m}$ : $\beta_{\|}=0.51$ for $\mathrm{O}-\mathrm{NO}^{+}$interaction and $\beta_{\|}=0.56$ for $\mathrm{O}^{+}-\mathrm{N}_{2}$ interaction. In the present paper, the ion temperature measured with the field-aligned beam was used. Under the assumption of a bi-Maxwellian ion velocity distribution, the neutral temperature was calculated from the parallel ion temperature $T_{i \|}$ by using Eq. (3) with $\beta_{\|}(=0.54)$ for both of the Troms $\varnothing$ and Svalbard radar data. As mentioned above, the isotropic treatment is more relevant for the period of a small electric field. The difference between the neutral temperatures derived from the isotropic and anisotropic assumptions, however, would be less than a few $\mathrm{K}$ in the case of an electric field of about $20 \mathrm{mV} / \mathrm{m}$; thus we believe the setting of the parameter $\beta_{\|}$of 0.54 does not affect our results significantly.

To obtain the neutral wind velocity in the E-region, the ion drift velocity was used together with the electric field de- 

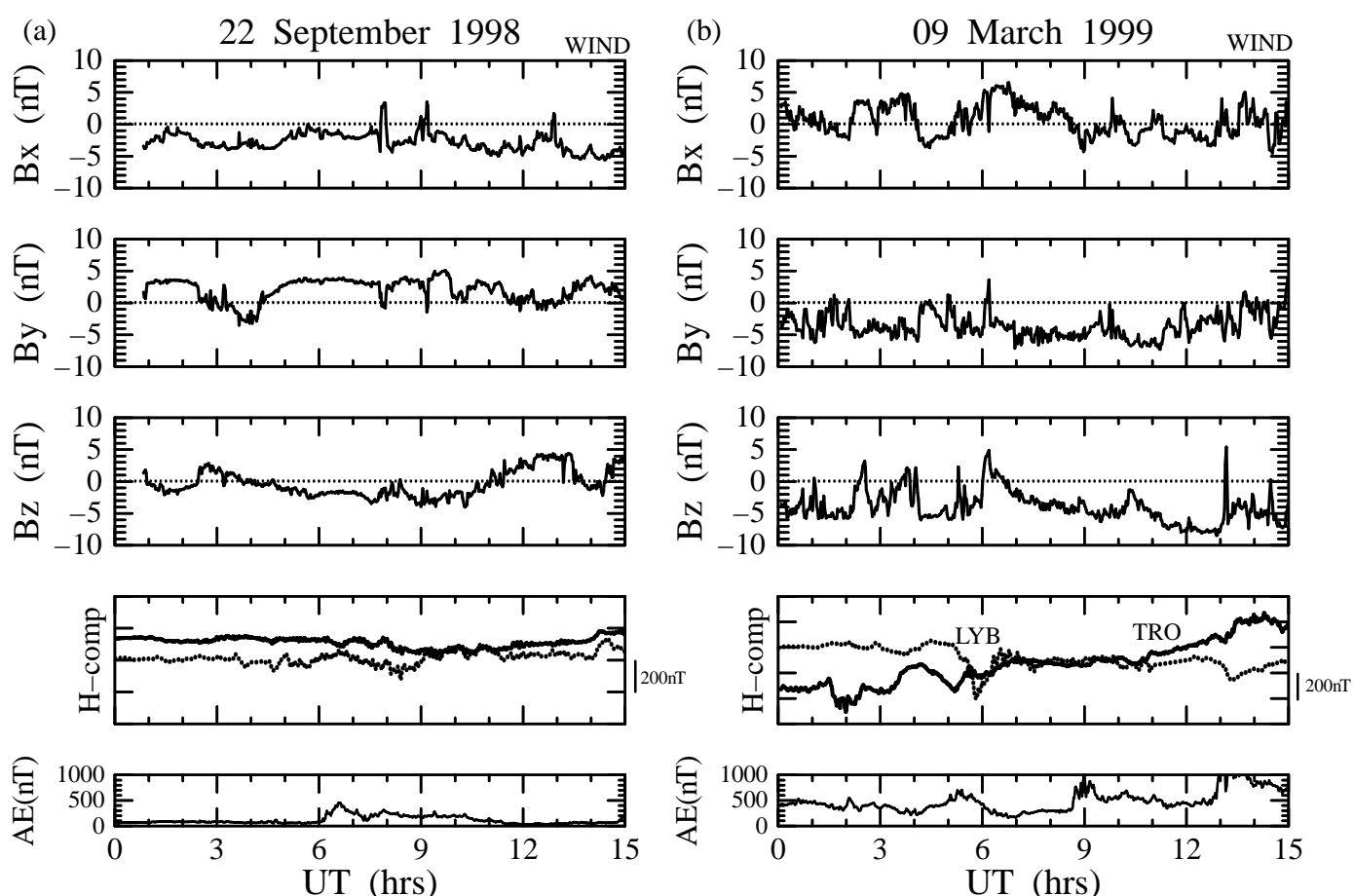

Fig. 1. From top to bottom: IMF $B_{x}, B_{y}$ and $B_{z}$ measured by the WIND spacecraft upstream in the solar wind, $H$-component of the magnetic field at Troms $\varnothing$ (TRO) and Longyearbyen (LYB) and $A E$-index on 22 September 1998 and 9 March 1999. The IMF data are corrected for a propagation delay from WIND and the Earth's magnetopause.

duced from the ion velocity data at about $278 \mathrm{~km}$ altitude, where ions and electrons are assumed to move by the $\boldsymbol{E} \times \boldsymbol{B}$ drift. The electric field was derived by combining the long pulse F-region monostatic ion velocity measurements with estimates of the magnetic field from the International Geomagnetic Reference Field (IGRF) model (International Association of Geomagnetism and Aeronomy Division I Working group 1,1987). Full ion velocity vectors were obtained by combining the three line of sight observations of the ion velocity, assuming that the velocity was uniform across the scattering volumes and did not vary over a cycle time of the antenna. The neutral horizontal velocity was derived from the steady-state ion momentum equation neglecting the ambipolar diffusion (Rino et al., 1977):

$\boldsymbol{V}_{n}=\boldsymbol{V}_{i}-\Omega_{i}\left(\boldsymbol{E}+\boldsymbol{V}_{i} \times \boldsymbol{B}\right) /\left(|\boldsymbol{B}| v_{i n}\right)$

where $\Omega_{i}=e|\boldsymbol{B}| / m_{i}$ and $e$ is the electrostatic charge $\left(=1.6 \times 10^{-19} \mathrm{C}\right)$. The ion-neutral momentum transfer collision frequency, $v_{i n}$, is calculated according to Schunk and Walker (1973). In deriving the neutral velocity from the measured ionospheric parameters, there is an uncertainty caused by the ion-neutral collision frequency (Williams et al., 1994). The best way to avoid such uncertainties is to use data taken under conditions of low electric fields and high signal to noise ratio in a limited height range below about $120 \mathrm{~km}$ (Kofman, 1992; Williams et al., 1994). Although the present analysis was limited to the region below $120 \mathrm{~km}$, it included the interval of electric field up to $80 \mathrm{mV} / \mathrm{m}$.
In usual IS spectrum fitting procedures, the Maxwellian distributions for both of the ion and electron populations are assumed and the ratio between the electron and ion temperatures below $107 \mathrm{~km}$ is given by a model. The EISCAT Troms $\varnothing$ and Svalbard radar data were analyzed by using the GUISDAP 1.65 analysis program (Lehtinen and Huuskonen, 1996) and the temperature ratio was given by a model where it is set to be 1.04 at $105 \mathrm{~km}$. If ions and electrons are in thermal equilibrium, the ion temperature should be equal to the electron temperature and consequently the temperature ratio is 1.0. The difference between the derived temperatures with different ratios (1.0 and 1.04) is less than a few percent and we believe the setting of the temperature ratio of 1.04 does not affect our results significantly. When a strong electric field is applied to the high-latitude E-region, however, this causes a modified two-stream instability, which heats the electron population (Schlegel and St.-Maurice, 1981; St.Maurice et al., 1981; Williams et al., 1992; Davies and Robinson, 1997; St.-Maurice and Kissack, 2000). In such a case of electron heating by the so-called Farley-Buneman waves, the ratio between the electron and ion temperature varies with time and in space. In the present analysis, an IS spectrum fitting was performed as follows: the ratio between the ion and electron temperatures even below $107 \mathrm{~km}$ was not fixed and the electron and ion temperatures were derived independently by using a modeled ion-neutral collision frequency when the electric field was greater than $20 \mathrm{mV} / \mathrm{m}$.

In this paper, we have used the data between 105 and $115 \mathrm{~km}$ during the periods of 00:00-15:00 UT (02:00- 


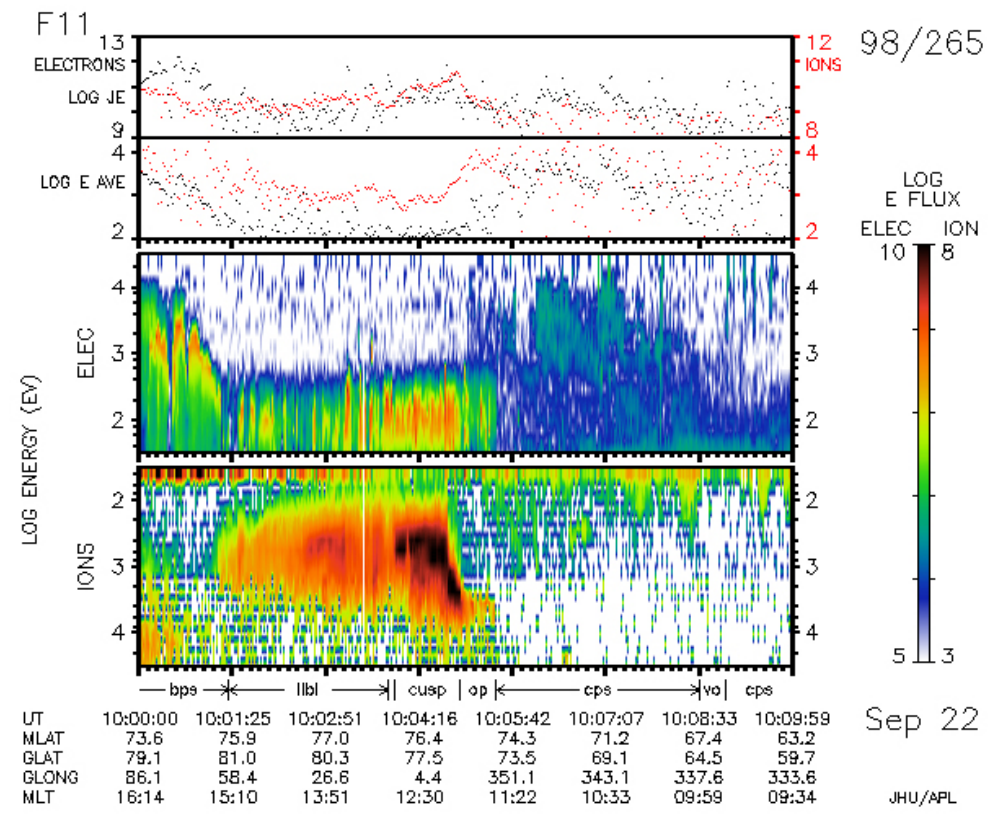

(a)

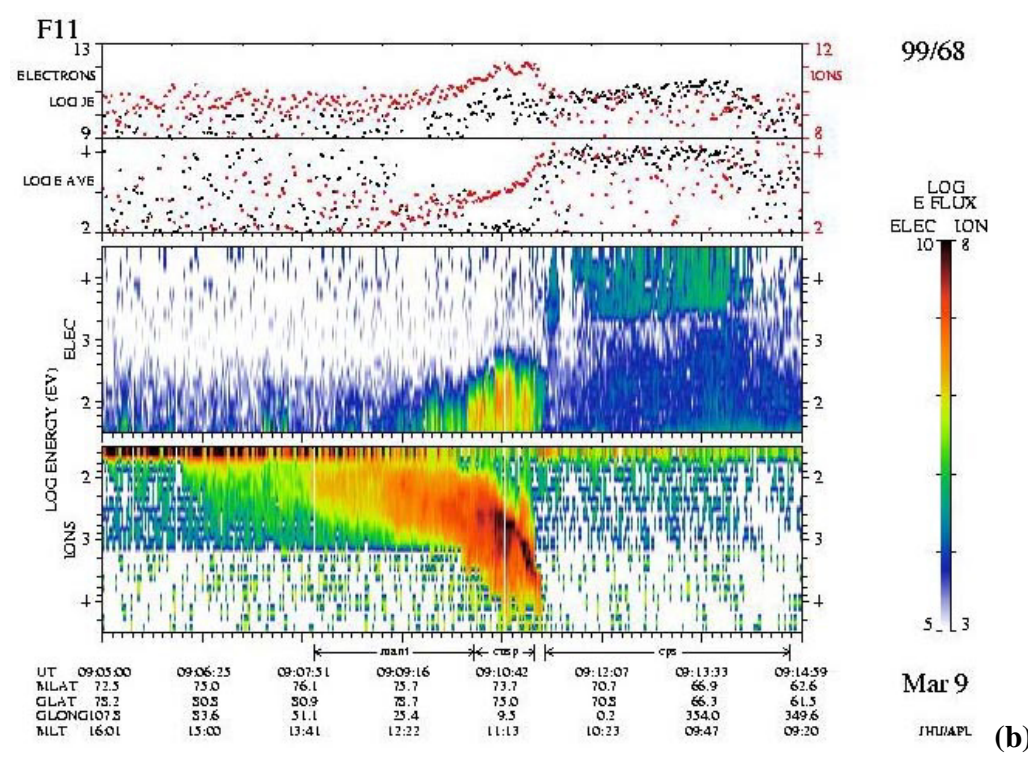

Fig. 2. DMSP F11 spectrograms of differential energy flux (eV/cm $\left.{ }^{2} \mathrm{~s} s t r\right)$. Top two line plots show total energy flux (eV/cm $\left.{ }^{2} \mathrm{~s} s t r\right)$ and average energy (eV) of ions (red) and electrons (black). Cusp particle precipitation was observed at the time of (a) 10:03-10:04 UT on 22 September 1998 and (b) 09:10-09:11 UT on 9 March 1999.

17:00 MLT at Troms $\varnothing$ and 03:00-18:00 MLT at Longyearbyen) on 22 September 1998 and 9 March 1999.

\section{IMF and geomagnetic conditions}

The three components of the interplanetary magnetic field (IMF) provided by the WIND spacecraft, are represented in the upper three panels of Figs. 1a and b. They are depicted in the geocentric solar magnetospheric (GSM) coordinate system corrected for propagation time to the Earth. The northward $(H)$ components of the magnetic field detected by ground-based magnetometers at Troms $\varnothing$ and Longyearbyen are shown in the 4th panels and the $A E$ index in the bottom panels, respectively. The IMF $B_{z}$ was about $-3 \mathrm{nT}$ from 05:00 to 11:00 UT and then turned to be positive up to $4 \mathrm{nT}$ on 22 September 1998. The IMF By was positive of about $5 \mathrm{nT}$ except for some negative excursions. On 9 March 1999, the IMF $B_{z}$ ranged from -8 to $-3 \mathrm{nT}$ except for some positive excursions. The IMF $B_{y}$ was negative by about $-5 \mathrm{nT}$.

As can be seen in the variations of the $H$ component at Troms $\varnothing$ and Longyearbyen, the geomagnetic activity was low on 22 September 1998. The magnitude of the variations was less than $50 \mathrm{nT}$ at Troms $\varnothing$ and less than $100 \mathrm{nT}$ at Longyearbyen. The $A E$ index, however, shows small activ- 

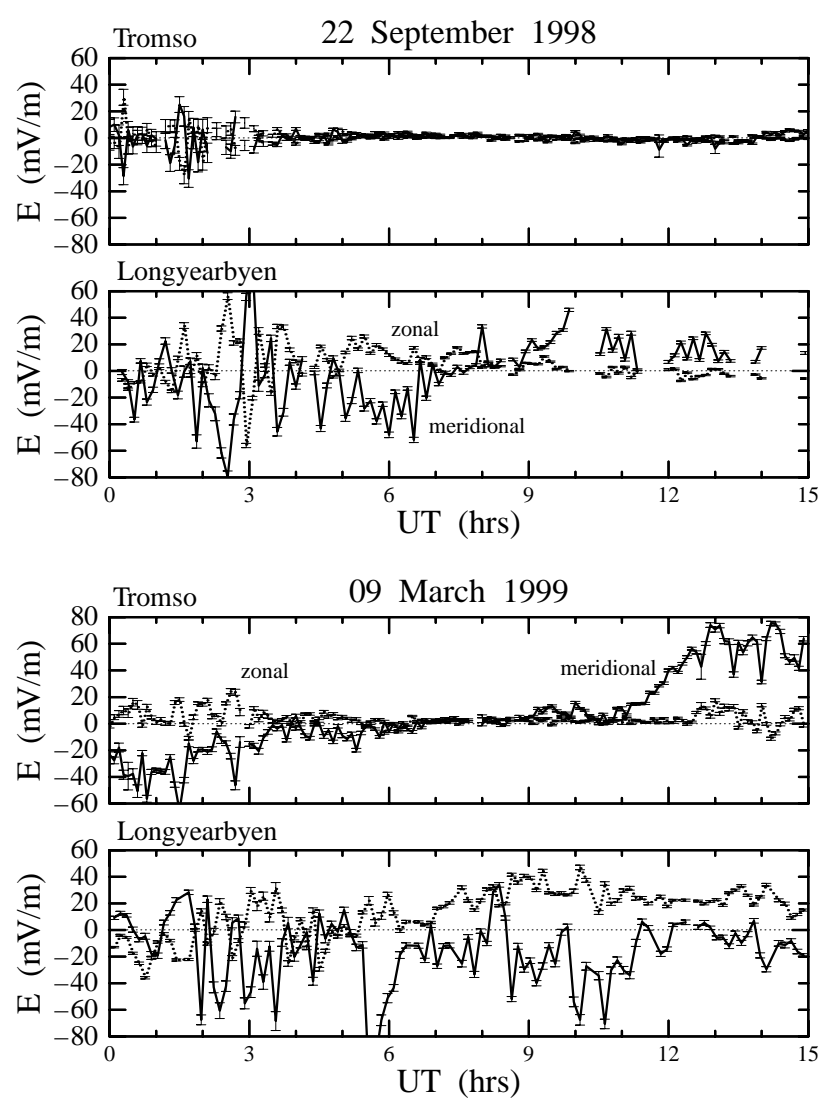

Fig. 3. Electric field strength measured by the EISCAT UHF radar at Troms $\varnothing$ (Troms $\varnothing$ radar) and the EISCAT Svalbard radar at Longyearbyen (Svalbard radar) between 00:00 and 15:00 UT on 22 September 1998 and 9 March 1999. The solid line represents the meridional component and the dotted line the zonal component. The positive values indicate the northward and eastward components, respectively.

ity just after 06:00 UT which seems to be related to magnetic disturbances in the night side since the magnetic activity at Troms $\varnothing$ and Longyearbyen was very small. In fact, some magnetic activity up to $500 \mathrm{nT}$ was observed in the Canadian sector by the Canadian Auroral Network for Open Unified Study (CANOPUS) magnetometer chain (not shown here). On the other hand, the magnetic activity was rather high on 9 March 1999. The $H$ component at Troms $\varnothing$ gradually increased with time from negative to positive. A negative variation of about $300 \mathrm{nT}$ was observed at Longyearbyen during 05:00-06:00 UT. There was an enhancement of the $A E$ index, at about 09:00 UT, which was due to magnetic activity in the night side since there was no significant activity at Troms $\emptyset$ and Longyearbyen corresponding to it. The data of the CANOPUS magnetometer chain exhibited magnetic activity of about a few hundreds of $\mathrm{nT}$ in the Canadian sector. The $A E$ index was up to $1000 \mathrm{nT}$ between 13:00 and 14:00 UT.

From the DMSP F11 particle data, cusp-type particle precipitation was observed just over the Svalbard radar site in both of the two periods, as shown in Fig. 2. At 10:03-
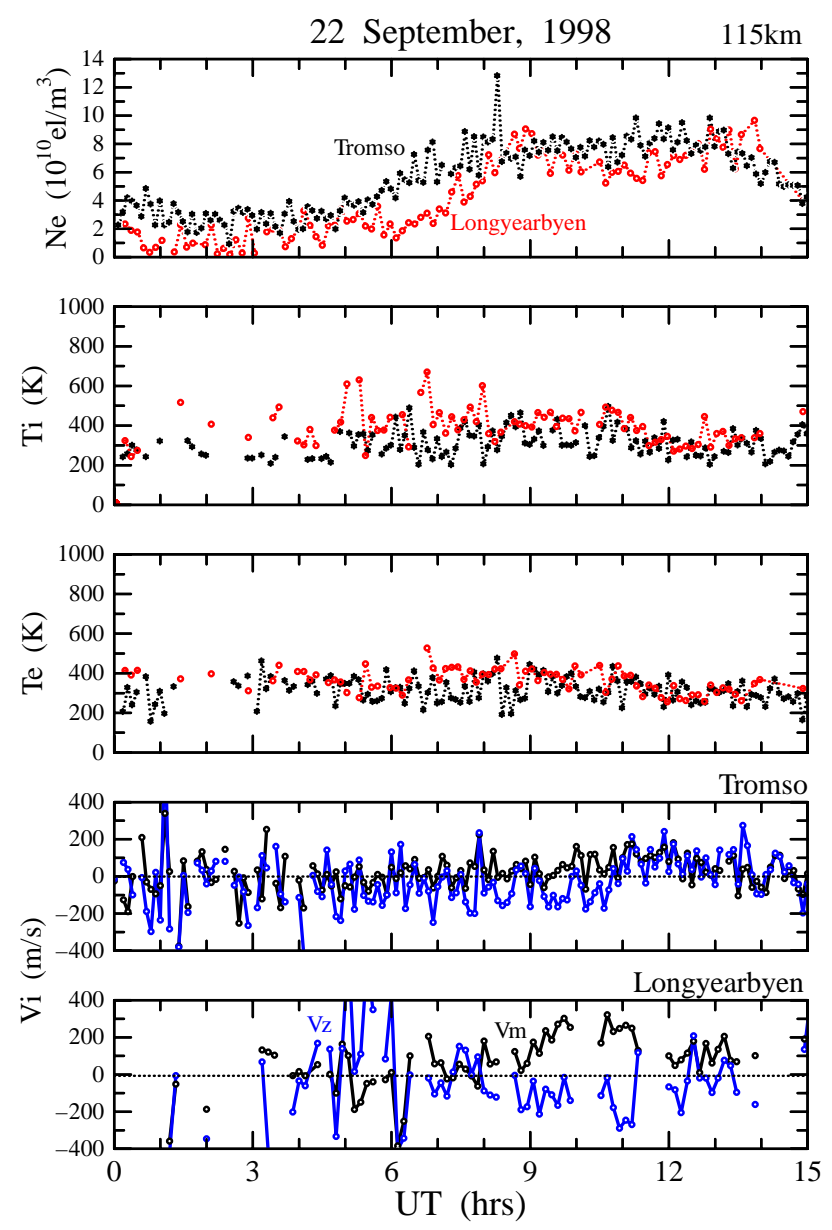

Fig. 4. Summary plots of the ionospheric parameters at $115 \mathrm{~km}$ altitude measured by the Troms $\varnothing$ radar and by the Svalbard radar from 00:00 to 15:00 UT on 22 September 1998. The top panel shows the electron density obtained from the field-aligned beam at Troms $\varnothing$ (black) and Longyearbyen (red). The ion and electron temperatures obtained from the field-aligned beam at Troms $\varnothing$ (black) and Longyearbyen (red) are shown in the second and third panels, respectively. The derived ion velocities at Troms $\varnothing$ and Longyearbyen are plotted in the fourth and fifth panels, respectively. The meridional component $\left(V_{m}\right)$ is shown by the black line, and the zonal component $\left(V_{z}\right)$ the blue line. The positive values indicate the northward and eastward components.

10:04 UT on the 22 September 1998, and at 09:10-09:11 UT on 9 March 1999, the ion precipitations with the 'normal dispersion' (lower particle energy at higher latitudes) characteristic of a spectrum of cusp particles (Smith and Lockwood, 1996) were detected. From inspection of the IMF condition and the DMSP particle data, it is inferred that the Svalbard radar was located beneath the low latitude boundary of the polar cap and the cusp region, while the Troms $\varnothing$ radar was in the auroral oval.

Figure 3 shows the convection electric fields given as functions of UT. On 22 September 1998, the electric field at Troms $\varnothing$ exhibited small fluctuations before 03:00 UT. After that, both of the meridional and zonal components were 
small and less than $5 \mathrm{mV} / \mathrm{m}$. In contrast, the electric field observed at Longyearbyen sometimes exceeded $30 \mathrm{mV} / \mathrm{m}$ and exhibited significant fluctuations. The direction varied from southeastward in the morning to northward in the afternoon. When a cusp passed over the Svalbard radar at about 10:03 UT, the northward electric field increased up to $45 \mathrm{mV} / \mathrm{m}$. On 9 March 1999, the electric field at Troms $\varnothing$ was less than $10 \mathrm{mV} / \mathrm{m}$ during the daytime but it was southward and up to $50 \mathrm{mV} / \mathrm{m}$ before 03:00 UT, and turned northward and up to $80 \mathrm{mV} / \mathrm{m}$ after 11:00 UT. These variations seem to be consistent with the so-called 'twin vortex' system of the convection electric field. At Longyearbyen, the meridional component was greater than $30 \mathrm{mV} / \mathrm{m}$ most of the time. The zonal component was also above $20 \mathrm{mV} / \mathrm{m}$ during the daytime. It is interesting to note that the daytime electric field, in the low latitude boundary of the polar cap and the cusp was greater and more variable than that in the auroral zone in these cases.

\section{Results}

Figure 4 represents the ionospheric parameters such as electron density, ion and electron temperatures and ion velocity at $115 \mathrm{~km}$ altitude measured by the Troms $\emptyset$ radar and the Svalbard radar on 22 September 1998. These data, except for the ion velocity, were obtained from the field-aligned beam. The ion velocity was derived by combining the three line of sight observations. The electron density shown in the top panel exhibited quiet-time daily variations at both of the two locations. The electron density at Troms $\varnothing$ was slightly higher than that at Longyearbyen. The ion temperature is depicted in the second panel. It can be seen that the ion temperature at Longyearbyen tended to be higher than that at Troms $\varnothing$; the difference between them was in the range from 100 to $200 \mathrm{~K}$ between 05:00 UT and 10:00 UT. The electron temperature shown in the third panel did not vary significantly with time. The electron temperature at Longyearbyen was higher than that at Troms $\varnothing$ between 06:30 and 10:30 UT.

The derived meridional and zonal components of the ion velocity at Troms $\varnothing$ and Longyearbyen are shown in the fourth and fifth panels, respectively. The positive values indicate northward and eastward velocities. The ion velocity at Troms $\varnothing$ was less than $200 \mathrm{~m} / \mathrm{sec}$ and the direction varied randomly with time. At Longyearbyen, however, the velocity variations were much larger than those at Troms $\varnothing$. When the Svalbard radar passed beneath the cusp region around 10:0310:04 UT, the electric field was northward and the E-region ion drift was northwestward.

The ionospheric parameters obtained at $115 \mathrm{~km}$ between 00:00 and 15:00 UT on 9 March 1999 are shown in Fig. 5. The electron density variations were quite different from quiet-time daily variations. Until 06:00 UT, the electron density at Troms $\emptyset$ was very high and fluctuated greatly. On the other hand, the electron density at Longyearbyen was very low before 06:00 UT. A hump can be seen at both stations between 05:30 and 08:00 UT. The electron density at Troms $\varnothing$
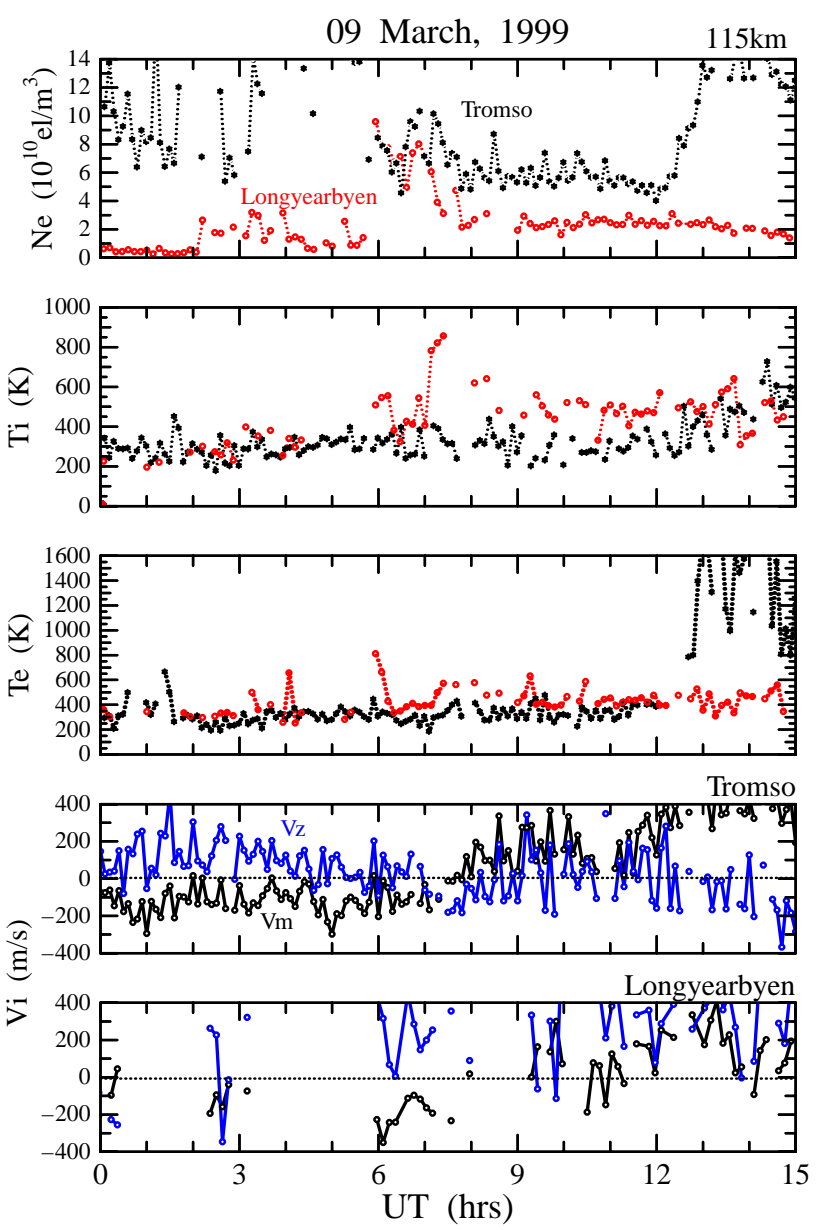

Fig. 5. Same parameters as Fig. 4 except for 9 March 1999.

was much higher than that at Longyearbyen. After 12:53 UT, the electron density at Troms $\varnothing$ increased to about three times than that between 08:00 and 12:00 UT. The large enhancement in the ionization in the dusk-side auroral region may be caused by the large geomagnetic disturbance seen in the $A E$ index of about $1000 \mathrm{nT}$ (see Fig. 1). In contrast, an enhancement of the ionization at Longyearbyen was not observed. The data of ion velocity as well as ion/electron temperatures at Longyearbyen were lacking particularly before 06:00 UT because of the low signal to noise ratio (large uncertainty) owing to the low electron density. The ion temperature at Longyearbyen increased simultaneously with the electron density enhancement between 06:00 and 08:00 UT. The ion temperature at Troms $\varnothing$, however, did not exhibit any significant increase. The ion temperature at Longyearbyen was also higher than that at Troms $\emptyset$ from 07:00 to 12:30 UT. The electron temperature variations were similar to those of the ion temperature except for the large enhancements of the electron temperature at Troms $\varnothing$ around 01:00 UT and after 13:00 UT. In particular, the electron temperature after 13:00 UT became more than $1000 \mathrm{~K}$.

The ion velocity at Troms $\varnothing$ shows a systematic variation from southeastward in the morning to northwestward in the 

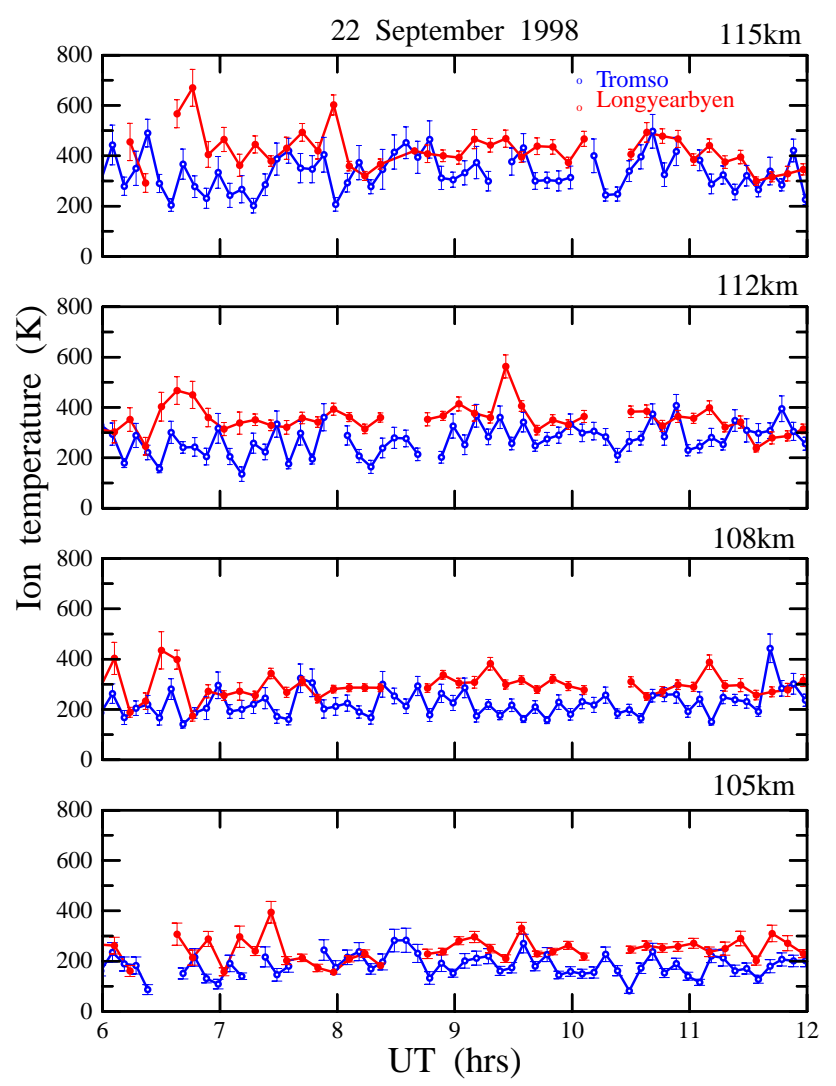

Fig. 6. Ion temperature parallel to the geomagnetic field between 105 and $115 \mathrm{~km}$ at Troms $\emptyset$ (blue) and Longyearbyen (red) from 06:00 to 12:00 UT on 22 September 1998. Error bars depict the rms random noise errors.

afternoon. As shown in Fig. 3, the convection electric field at Troms $\varnothing$ was southward in the morning and became northward after 11:00 UT. The ion flow at Troms $\varnothing$ seems to be consistent with the convection electric field when the effect of ion-neutral collision on the E-region ion motion is taken into account. The ion velocity at Longyearbyen was southeastward between 06:00 and 08:40 UT, this turned northeastward after 11:00 UT. The electric field during these two periods was southeastward and eastward, respectively, as shown in Fig. 3. The northeastward ion flow after 11:00 UT could be driven by the eastward electric field. It seems, however, that the southeastward ion flow between 06:00 and 08:40 UT was not consistent with the observed southeastward electric field.

The ion and neutral temperatures and related energy budget between 06:00 and 12:00 UT will be discussed in Sect. 5.1. One of the reasons why the discussion has been restricted to only the daytime is the lack of nighttime data at Longyearbyen. Another reason for this is to avoid the data during the period of high geomagnetic activity after 12:00 UT on 9 March 1999.
Table 2. Weighting function

\begin{tabular}{cc}
\hline Number of Points & Weight \\
-2 & -3 \\
-1 & 12 \\
0 & 17 \\
1 & 12 \\
2 & -3 \\
\hline
\end{tabular}

\subsection{Ion temperature and ion energy budget}

Figure 6 shows the ion temperature in the altitude range from 105 to $115 \mathrm{~km}$ plotted as a function of UT on 22 September 1998. Associated errors (rms random noise errors) with individual data values are also shown. The errors were mostly less than $50 \mathrm{~K}$. The ion temperature at Troms $\varnothing$ was almost constant with the fluctuations of less than $50 \mathrm{~K}$ at and below $112 \mathrm{~km}$. The average temperature was about $200 \mathrm{~K}$ at 105 and $108 \mathrm{~km}$, and $250 \mathrm{~K}$ at $112 \mathrm{~km}$. At the altitude of $115 \mathrm{~km}$, it was about $350 \mathrm{~K}$. The magnitude of the variations was slightly greater than that in the lower region. The ion temperature at Longyearbyen was higher than that at Troms $\varnothing$ most of the time. The temperature difference between the two locations was about 100-200 K.

The ion temperature on 9 March 1999 is shown in Fig. 7. The mean values of the ion temperature at Troms $\varnothing$ were similar to those on the 22 September 1998, but the variations were rather irregular. In spite of data gaps, it is observed that the ion temperature at Longyearbyen was higher than that at Troms $\varnothing$ from 07:10 to 11:20 UT. The temperature difference was much greater than $100 \mathrm{~K}$ and sometimes exceeded $300 \mathrm{~K}$. The maximum temperature difference at $115 \mathrm{~km}$ was about $500 \mathrm{~K}$ at 07:24 UT.

In order to examine the ion energy budget, the ion frictional heating given in Eq. (3) was derived from the measured ion velocity and the neutral wind velocity calculated by using Eq. (6). It should be noted that the ion velocity obtained from the EISCAT CP-2 data sometimes scatters significantly (Nozawa and Brekke, 2000). To reduce the rms randomnoise errors involved in measuring the ion velocity, the data of the ion velocity were smoothed with five point running averages ( $30 \mathrm{~min}$ for the Troms $\varnothing$ radar data and $40 \mathrm{~min}$ for the Svalbard radar data) by using a weighting function of the Savitzky-Golay method given in Table 2. Another reason for the smoothing is the fact that the time constant for the neutrals to approach the ion velocity is of the order of magnitude $10^{4} \mathrm{~s}$ in the E-region (Brekke, 1997) and the neutrals cannot respond quickly to electromagnetic variations. Since the steady-state ion energy equation has been used to derive the neutral temperature in the present analysis, the time constant of the neutrals cannot be estimated in a consistent manner. In running averaging, ion velocity data having rms randomnoise error greater than $500 \mathrm{~m} / \mathrm{s}$ were excluded.

Figure 8 shows the magnitude of the ion frictional heating 


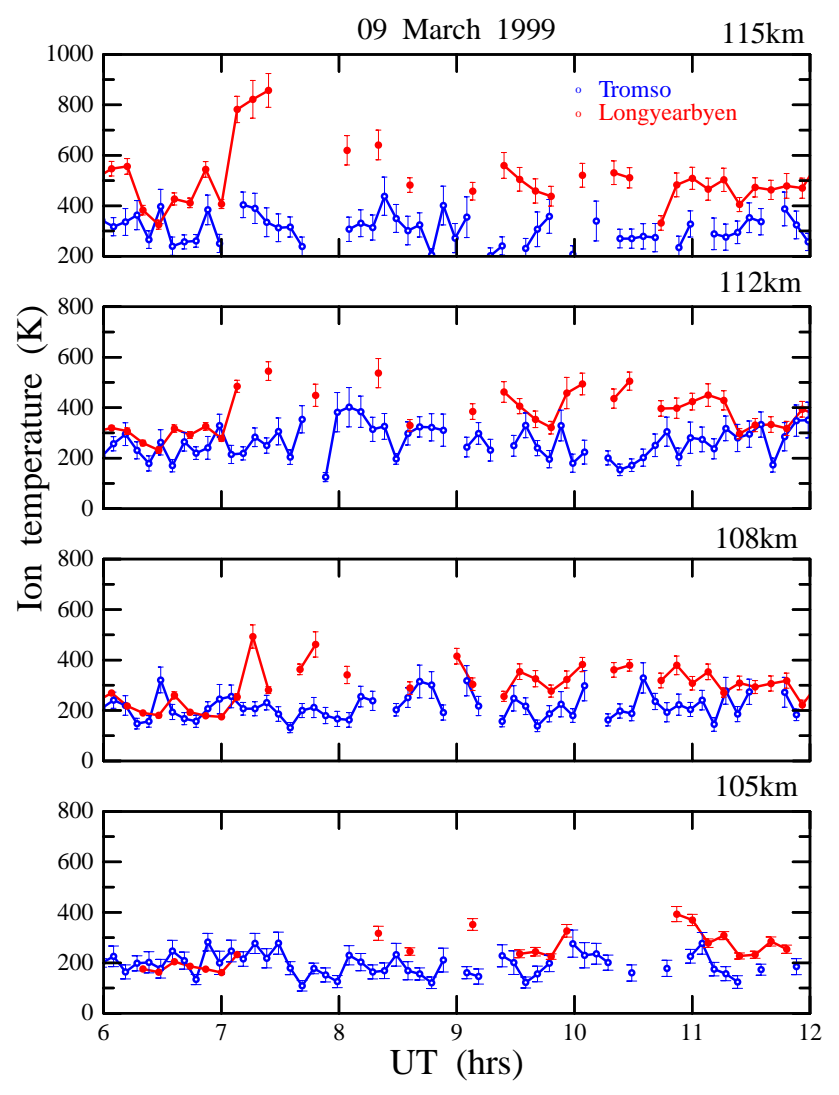

Fig. 7. Same as Fig. 6 except for 9 March 1999.

at an altitude of $115 \mathrm{~km}$ from 06:00 to 12:00 UT in the case of $\beta_{\|}=0.54$. As already mentioned in Sect. 3 , the ion temperature at Troms $\varnothing$ would be isotropic since the electric field was very small most of the time. The ion frictional heating assuming the isotropic ion temperature $\left(\beta_{\|}=2 / 3\right)$, was about $20 \%$ greater than in the anisotropic case. The difference between them, however, was negligibly small because of the small electric field and resultant small ion frictional heating. For the event on the 22 September 1998, the magnitude of the frictional heating at Troms $\varnothing$ was negligibly small, less than $5 \mathrm{~K}$, since the electric field was small during this particular period, while at Longyearbyen it was larger than that at Troms $\varnothing$; more than $20 \mathrm{~K}$ from 09:00 to 09:52 UT and from 10:32 to 11:20 UT. On 9 March 1999, the magnitude of the ion frictional heating at Troms $\varnothing$ was less than $10 \mathrm{~K}$ before 08:30 UT, and then increased to be $20 \mathrm{~K}$ by $10: 06 \mathrm{UT}$. This became large after 11:00 UT, being about $90 \mathrm{~K}$ at 12:00 UT. At Longyearbyen, ion frictional heating of about $\sim 200 \mathrm{~K}$ at 06:06 UT and of $\sim 64 \mathrm{~K}$ at 09:18 UT was derived. Owing to the large eastward ion flow of about $400 \mathrm{~m} / \mathrm{s}$ at 11:02 UT (see Fig. 5), the ion frictional heating was enhanced to be $110 \mathrm{~K}$. In contrast to the Troms $\varnothing$ case, the ion frictional heating at Longyearbyen decreased after 11:00 UT. The time variations of the ion frictional heating at the two stations generally corresponded well with those of the electric field at each station.

The present results imply that the enhancement of the electric field and resultant ion frictional heating in the afternoon
Frictional Heating
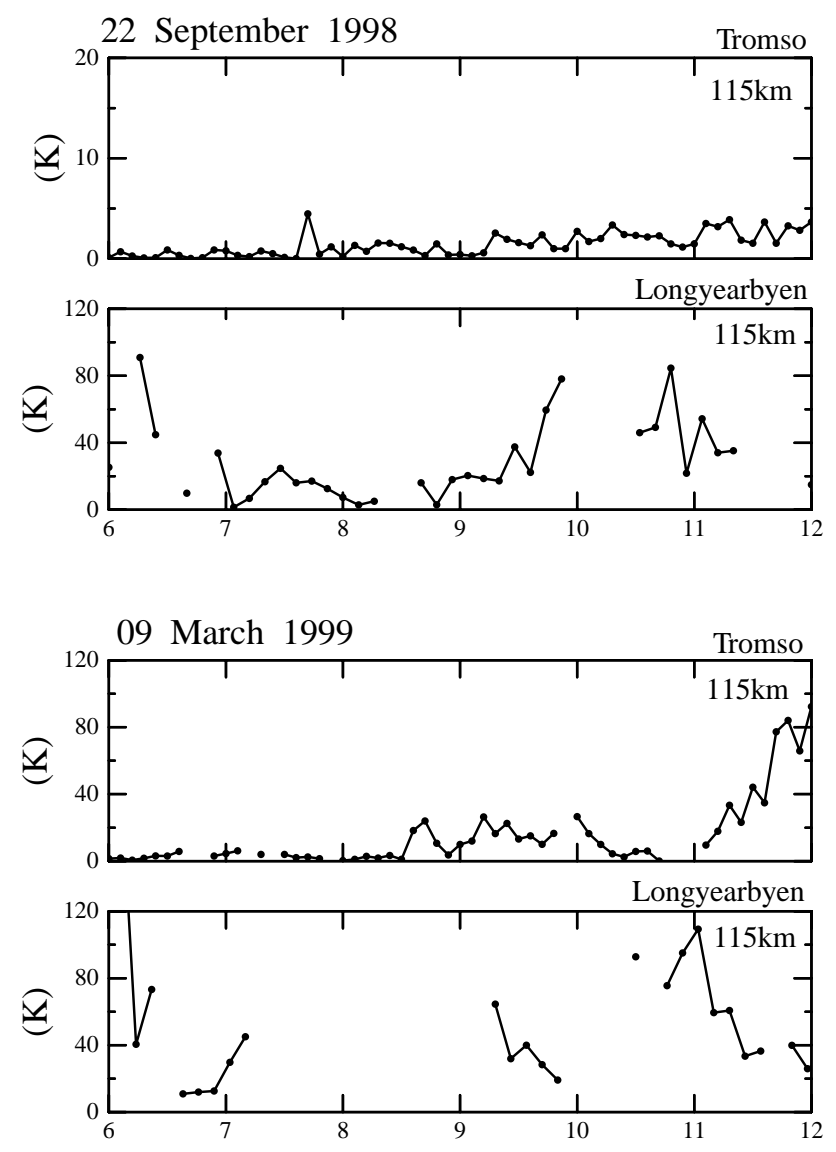

UT (hrs)

Fig. 8. Ion frictional heating $\beta_{\|} m_{n}\left(\boldsymbol{V}_{i}-\boldsymbol{V}_{n}\right)^{2} /\left(2 \kappa_{B}\right)$ in Kelvin units at $115 \mathrm{~km}$ between 06:00 and 12:00 UT at Troms $\varnothing$ and Longyearbyen on 22 September 1998 (the upper two panels) and 9 March 1999 (the lower two panels). The ion and neutral velocities used to estimate the ion frictional heating were smoothed with five point running averages.

sector occurred mainly in the auroral region but not in the polar cap and/or at the low latitude boundary of the polar cap. This seems to be consistent with the statistics by Davies et al. (1997) showing that significant heating in the auroral Fregion is observed primarily during night-time and not during daytime. The significant dayside heating in the E-region at Longyearbyen was quite distinctive.

It is important to examine whether or not the heat exchange between ions and electrons can be negligible with respect to the ion energy budget. As discussed in Sect. 3, electron heating by the Farley-Buneman waves occurs when the electric field strength is greater than $20 \mathrm{mV} / \mathrm{m}$ (Williams et al., 1992; Davies and Robinson, 1997). Figure 9 shows the ion and electron temperatures at Longyearbyen. There are some occasions when the electron temperature was higher than the ion temperature at 108 and $112 \mathrm{~km}$ between 06:00 UT and 08:00 UT in both of the two periods. In ad- 
22 September, 1998

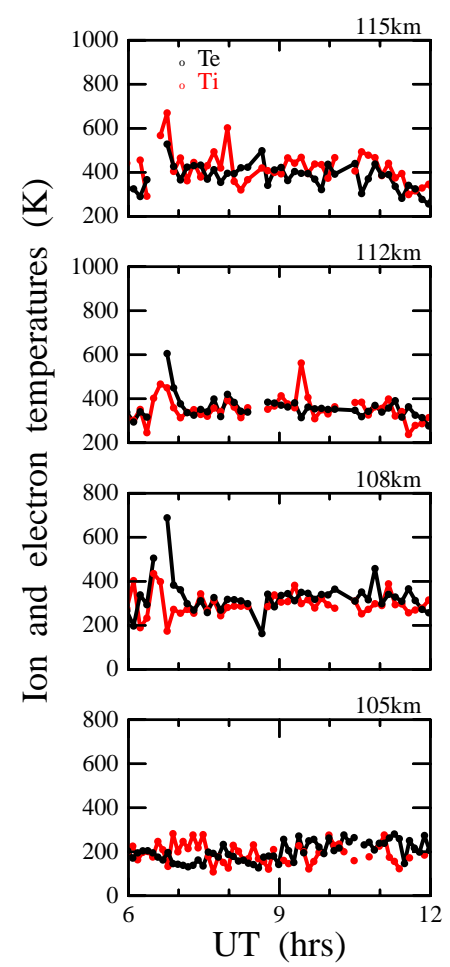

09 March, 1999
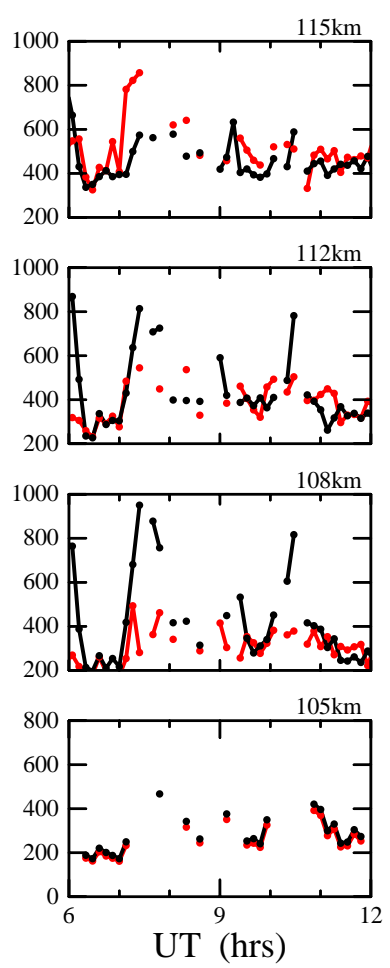

Fig. 9. Electron (black) and ion (red) temperatures at Longyearbyen obtained by the field-aligned beams between 105 and $115 \mathrm{~km}$ from 06:00 to 12:00 UT on 22 September 1998 (left) and 9 March 1999 (right).

dition, there was some other electron heating between 09:00 and 11:30 UT on March 09, 1999. The electron temperature at $108 \mathrm{~km}$ reached $950 \mathrm{~K}$ at $07: 24 \mathrm{UT}, 670 \mathrm{~K}$ higher than the ion temperature. It is interesting to note that in most of the periods, except for 08:00-09:30 UT, the electron temperature was lower than the ion temperature at the altitudes of 105 and $115 \mathrm{~km}$. The contribution of the electron heating on the ion energy budget was calculated by the third term on the righthand side of Eq. (2), assuming $m_{n}=m_{i}$, by utilizing the measured ion and electron temperatures. The ion-electron collision frequency $v_{i e}$ appearing in this term was computed from the formula for $v_{e i}$ given by Kelly (1989) and Brekke (1997) using the relation $n_{i} m_{i} v_{i e}=n_{e} m_{e} v_{e i}$ (Shunk and Nagy, 2000). The measured electron density and temperature were used to compute the ion-electron collision frequency assuming $n_{i}=n_{e}$. The maximum contribution of the electron heating to the ion energy budget was of the order of magnitude of $10^{-3} \mathrm{~K}$. Therefore, it is concluded that the neglect of the electron heating in the Eq. (2) does not cause a significant overestimation of the neutral temperature for the present data set.

\subsection{Neutral temperature and neutral energy budget}

Figure 10 shows the neutral temperature from 06:00 to 12:00 UT on 22 September 1998 derived from the ion tem-

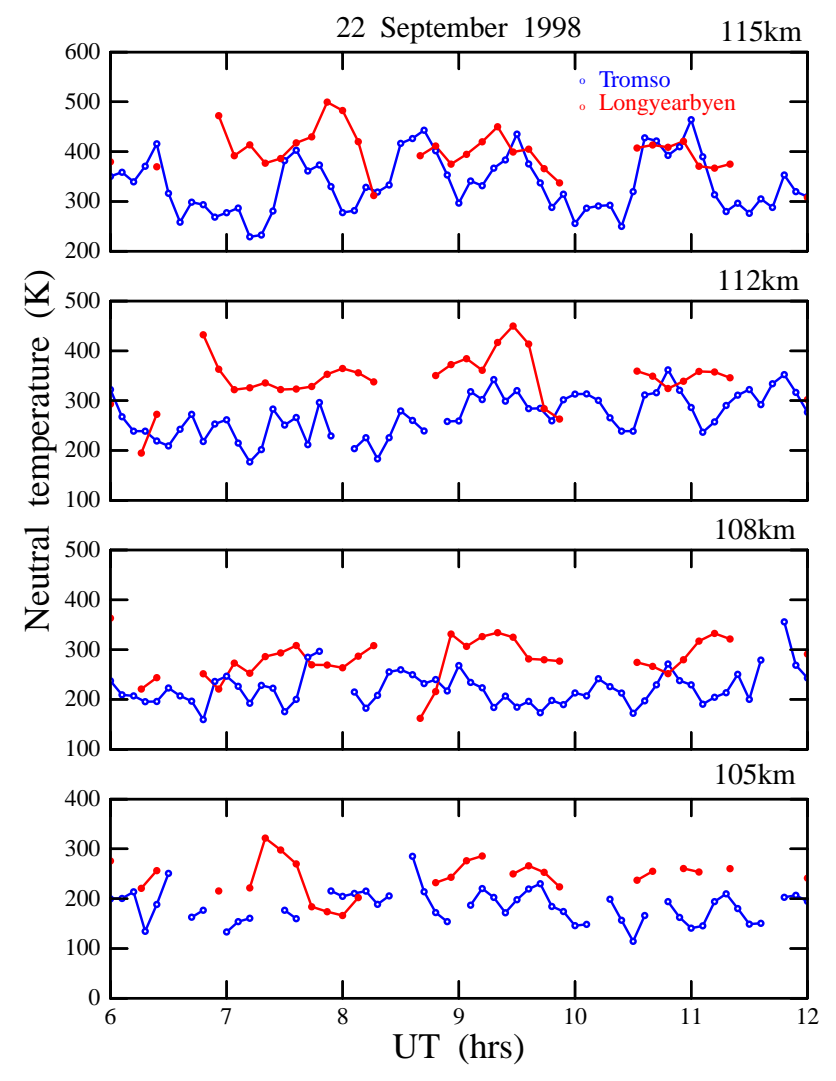

Fig. 10. Derived neutral temperatures between 105 and $115 \mathrm{~km}$ at Troms $\varnothing$ (blue) and Longyearbyen (red) from 06:00 to 12:00 UT on 22 September 1998.

perature and ion frictional heating using Eq. (3). It should be noted here that the estimated neutral temperature might include the effects of heat transport, time variations and viscous heating represented by the terms on the left hand side of Eq. (1) when they were not negligibly small. According to the running averaged ion and neutral velocities, the ion temperature was also smoothed with a five point running average in deriving the neutral temperature. Here, the data of ion temperature having the rms random-noise error greater than $100 \mathrm{~K}$ were excluded. The average temperatures at Troms $\varnothing$ were $200 \mathrm{~K}$ at 105 and $108 \mathrm{~km}, 250 \mathrm{~K}$ at $112 \mathrm{~km}$ and $350 \mathrm{~K}$ at $115 \mathrm{~km}$. The neutral temperature at Longyearbyen was generally higher than that at Troms $\varnothing$ at all altitudes. The magnitude of the temperature difference between the two locations was about $100 \mathrm{~K}$, except for the times around 08:30 UT and 10:50 UT when there was no significant difference. At $115 \mathrm{~km}$ altitude, the neutral temperature at Troms $\emptyset$ exhibited wavelike oscillations with a period of about one hour. Except for these oscillations, it is inferred that the neutral temperature at Troms $\varnothing$ was lower than that at Longyearbyen. Unfortunately, the Svalbard radar data were not available from 08:20 to 08:40 UT and from 10:00 to 10:30 UT; thus, it is not obvious whether the neutral temperature at Longyearbyen showed wavelike oscillations similar to those at Troms $\varnothing$. Therefore, the relationship between 


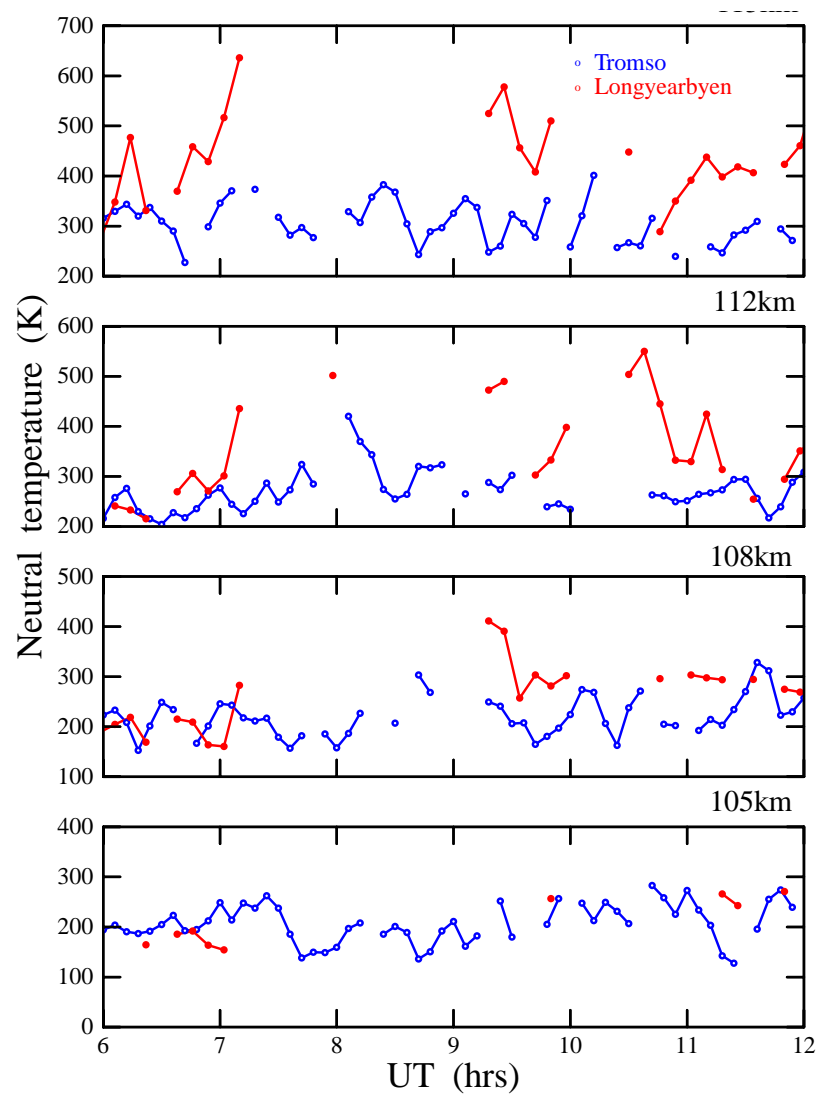

Fig. 11. same as Fig. 10 except for 9 March 1999.

the neutral temperatures at Troms $\varnothing$ and Longyearbyen mentioned above may not be conclusive at $115 \mathrm{~km}$ altitude.

Figure 11 represents the neutral temperatures from 06:00 to 12:00 UT on 9 March 1999. The neutral temperature at Troms $\varnothing$ exhibited irregular variations. The averaged temperature was $200 \mathrm{~K}$ at 105 and $108 \mathrm{~km}, 250 \mathrm{~K}$ at $112 \mathrm{~km}$ and $300 \mathrm{~K}$ at $115 \mathrm{~km}$. Since the ion velocity at Longyearbyen was not always available, particularly in the lower altitude region, the neutral temperature could not be derived on such occasions. In spite of the large data gaps, it was found that the estimated neutral temperature at Longyearbyen was significantly higher than that at Troms $\varnothing$ around 07:00 UT and after 09:20 UT. The temperature difference at $115 \mathrm{~km}$ reached $320 \mathrm{~K}$ at 09:26 UT. These results seem to be consistent with previous observations of the F-region temperature maximum over the polar cap and at the cusp (Hays et al., 1984; McCormac et al., 1988). The present results also show the higher temperature in the dayside polar cap boundary and the cusp than the auroral region even in the E-region.

The high temperature over the F-region polar cap was speculated to be a direct consequence of the Joule and soft particle heating in the polar cusp and thermal advection by the polar cap winds (Hays et al., 1984; McCormac et al., 1988). It is not obvious whether the physical mechanisms responsible for the hot polar cap and cusp in the E-region are the same as those in the F-region. However, it is quite reason-
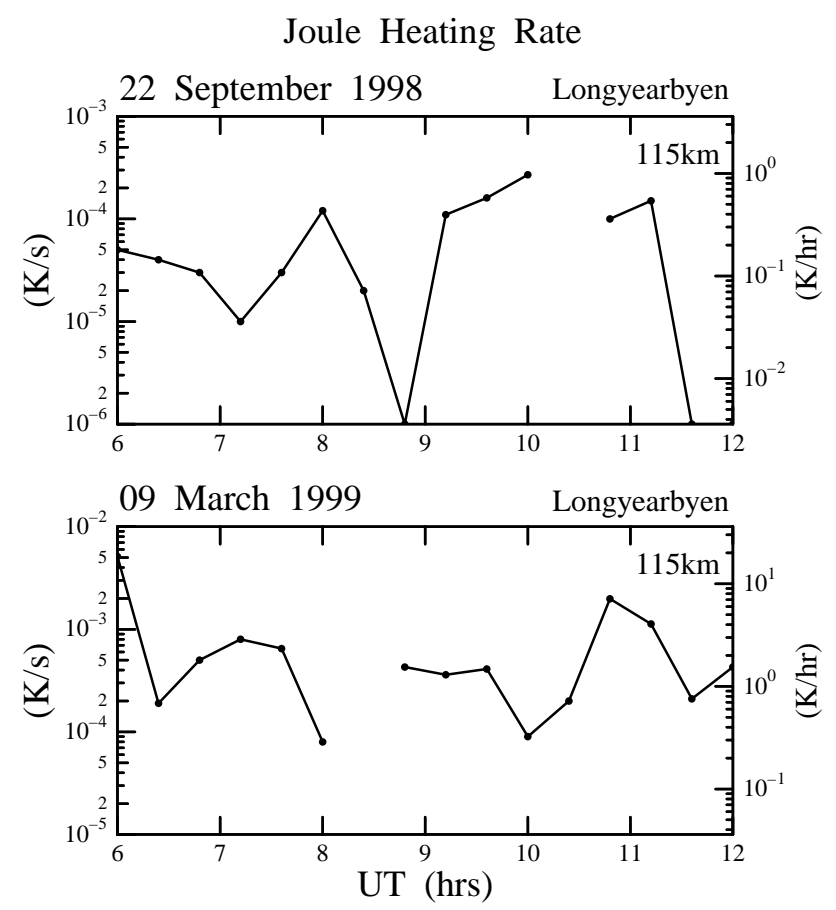

Fig. 12. Joule heating rate at $115 \mathrm{~km}$ altitude at Longyearbyen from 06:00 to 12:00 UT on 22 September 1998 (top) and 9 March 1999 (bottom).

able to infer Joule heating as one of the major heat sources. For a comparison between the neutral temperature increase and the Joule heating rate at Longyearbyen, the Joule heating rate was evaluated by using Eq. (5). Figure 12 exhibits the Joule heating rate between 06:00 and 12:00 UT at $115 \mathrm{~km}$. The Joule heating rate on 22 September 1998 lay in the range between $10^{-6}$ and $10^{-3} \mathrm{~K} / \mathrm{sec}$. On 9 March 1999 , it was greater by one order of magnitude than that on 22 September 1998. In both periods, however, the temperature increase of more than $100 \mathrm{~K}$ can hardly be explained from the estimated Joule heating rate. The Joule heating, estimated locally, was insufficient to the cause of the temperature increase. It is still encouraging to find that the time variations of the Joule heating rate were not much different from those of the neutral temperature.

It would be rather surprising to see the neutral temperature above $500 \mathrm{~K}$ in the altitude region of about $115 \mathrm{~km}$. If the neutral energy balance cannot be attained locally and the effect of heat transport by the polar cap neutral winds is important as discussed by Hays et al. (1984) and McCormac et al. (1988), we cannot neglect the effect of the heat transport depicted in the terms on the left-hand side of Eq. (5). In such a case, the neutral temperature estimated in this analysis is considered to be the sum of 'real' neutral temperature and contribution of the heat transport. Another problem concerning the data analysis is the assumption of spatial and temporal uniformity of the ion velocity over the area of four scattering volumes and the cycle time, which is inherent to the analysis of the CP-2 data. The effect of solar heating was not consid- 
ered in speculating the reason why the neutral temperature at Longyearbyen was higher than that at Troms $\varnothing$, because solar heating was stronger at lower latitudes and could not cause the higher temperature at higher latitudes.

\section{Summary and conclusions}

Two sets of simultaneous EISCAT CP-2 measurements, between 00:00 and 15:00 UT on 22 September 1998 and 9 March 1999 by the Troms $\varnothing$ radar and the Svalbard radar, have been used to investigate the distributions of the ion and neutral temperatures in the E-region in relation to the IMF condition and the convection electric field. From inspection of the IMF condition and the DMSP particle data, it is inferred that Longyearbyen was located beneath the low latitude boundary of the polar cap and the cusp region but Troms $\varnothing$ in the auroral oval.

The neutral temperature during the daytime (between 06:00 and 12:00 UT) was estimated from the measured ion temperature by using the steady-state ion energy equation under the assumption that the effects of heat transfer and viscous heating were negligibly small. The results are summarized as follows:

1. The electric field observed at Longyearbyen was greater and more variable than that at Troms $\varnothing$ during the daytime.

2. The parallel ion temperature $T_{i \|}$ at Longyearbyen was higher than that at Troms $\emptyset$ during the daytime. The difference between them was about $100-200 \mathrm{~K}$ but sometimes exceeded $300 \mathrm{~K}$.

3. Ion frictional heating at Troms $\varnothing$ was small during the daytime but increased largely in the dusk sector when the magnetic activity was high. The ion frictional heating at Longyearbyen was greater than that at Troms $\varnothing$ during the daytime but did not increase in the dusk sector even during the period of high magnetic activity.

4. Electron heating was observed at 108 and $112 \mathrm{~km}$, but not at 105 and $115 \mathrm{~km}$. The contribution of the electron heating to the ion energy budget, however, was negligibly small.

5. Similar to the ion temperature, the estimated neutral temperature at Longyearbyen was also higher than that at Troms $\varnothing$ by more than $100 \mathrm{~K}$.

6. The estimated Joule heating rate at Longyearbyen lay in the range between $10^{-6}$ and $10^{-2} \mathrm{~K} / \mathrm{sec}$, which seemed to be insufficient to explain the enhancement in the estimated neutral temperature.

Two possibilities can be suggested: the neutral temperature was high in the low latitude boundary of the polar cap and the cusp, or the heat transport by the polar cap neutral winds toward the dayside sector was significantly large.
Acknowledgements. We are indebted to the director and staff of EISCAT for operating the facility and supplying the data. EISCAT is jointly funded by the Particle Physics and Astronomy Research Council (UK), Centre National de la Recherche Scientifique (France), Max-Plank Gesellschaft (F.R.G.), Suomen Akatemia (Finland), National Institute of Polar Research (Japan), Norges Almenvitenskapelige Forskningsråd (Norway), and Naturvetenskapliga Forskningsrådet (Sweden). Thanks also to the staff of CDA web, and WDC-C2, Kyoto University for providing public WIND satellite data and geomagnetic indices, respectively. The IMAGE data was kindly supplied by the Auroral Observatory, University of Troms $\varnothing$. The DMSP particle detectors were designed by Dave Hardy of AFRL, and obtained from JHU/APL. We thank Dave Hardy, Fred Rich, and Patrick Newell for its use. The CANOPUS instrument array constructed, maintained and operated by the Canadian Space Agency, provided the data used in this study. We really appreciate Dr Yasunobu Ogawa for his great help and discussions.

Topical Editor M. Lester thanks two referees for their help in evaluating this paper.

\section{References}

Balmforth, H. F., Moffett, R. J., and Rodger, A. S.: Localized structure in the cusp and high-latitude ionosphere: a modelling study, Ann. Geophysicae, 17, 455, 1999.

Banks, P. M.: Energy sources of the high latitude upper atmosphere, in Exploration of the Polar Upper Atmosphere, (Eds) Deehr, C. S. and Holtet, J. A., D. Reidel Publishing Company, p. 113, 1980.

Banks, P. M. and Kockarts, G.: Aeronomy, part B, Academic, San Diego, Calif., p. 6, 1973.

Brekke, A.: Physics of the Upper Polar Atmosphere, John Willy \& Sons Ltd, New York, 1997.

Brekke, A. and Rino, C. L.: High-resolution altitude profiles of the auroral zone energy dissipation due to ionospheric currents, J. Geophys. Res., 83, 2517, 1978.

Davies, J. A., Lester, M., and McCrea, I. W.: A statistical study of ion frictional heating observed by EISCAT, Ann. Geophysicae, 15, 1399, 1997.

Davies, J. A. and Robinson, T. R.: Heating of the high-latitude ionospheric plasma by electric fields, Adv. Space Res., 20, 1125, 1997.

Folkestad, K., Hagfors, T., and Westerlund, S.: EISCAT: An updated description of technical characteristics and operational capabilities, Radio Sci., 18, 867, 1983.

Fujii, R., Nozawa, S., Matuura, N., and Brekke, A.: Study on neutral wind contribution to the electrodynamics in the polar ionosphere using EISCAT CP-1 data, J. Geophys. Res., 103, 14731 , 1998.

Fujii, R., Nozawa, S., Buchert, S., and Brekke, A.: Statistical characteristics of electromagnetic energy transfer between the magnetosphere, the ionosphere, and the thermosphere, J. Geophys. Res., 104, 2357, 1999.

Fujii, R., Nozawa, S., Buchert, S., and Brekke, A.: Energy coupling between the magnetosphere, ionosphere and thermosphere, Adv. Space Res., 25(1), 213, 2000.

Hays, P. B., Killeen, T. L., Spencer, N. W., Wharton, L. E., Roble, R. G., Emery, B. A., Fuller-Rowell, T. J., Rees, D., Frank, L. A., and Craven, J. D.: Observations of the dynamics of the polar thermosphere, J. Geophys. Res., 89, 5597, 1984.

IAGA Division I Working Group 1: International geomagnetic reference field revision 1987, J. Geomagn. Geoelectr., 39, 773, 
1987.

Kelly, M. C.: The Earth's Atmosphere: Plasma physics and electrodynamics, Academic press, New York, p. 34, 1989.

Killeen, T. L., Hays, P. B., Carignan, G. R., Heelis, R. A., Hanson, W. B., Spencer, N. W., and Brace, L. H.: Ion-neutral coupling in the high-latitude F-region: Evaluation of ion heating terms from Dynamics Explorer 2, J. Geophys. Res., 89, 7495, 1984.

Kofman, W.: Auroral ionospheric and thermospheric measurements using the incoherent scatter technique, Surv. Geophys., 13, 551, 1992.

Lathuillere, C. and Hubert, D.: Ion composition and ion temperature anisotropy in periods of high electric fields from incoherent scatter observations, Ann. Geophysicae, 7, 285, 1989.

Lehtinen, M. and Huuskonen, A.: General incoherent scatter analysis and GUISDAP error estimates valid for high signal strength, J. Atmos. Terr. Phys., 58, 435, 1996.

Lockwood, M., Bromage, B. J. I., Horne, R. B., St.-Maurice, J. P., Willis, D. M., and Cowley, S. W. H.: Non-Maxwellian ion velocity distributions observed during EISCAT, Geophys. Res. Lett., 14, 111, 1987.

Lu G., Richmond, A. D., Emery, B. A., and Roble, R. G.: Magnetosphere-ionosphere-thermosphere coupling: Effect of neutral winds on energy transfer and field-aligned current, J. Geophys. Res., 100, $19643,1995$.

Maeda, S., Fujiwara, H., and Nozawa, S.: Momentum balance of dayside E-region neutral winds during geomagnetically quiet summer days, J. Geophys. Res., 104, $19871,1999$.

McCormac, F. G., Killeen, T. L., Burns, A. G., and Meriwether, J. W., Roble, R. G., Wharton, L. E., and Spencer, N. W.: Polar cap diurnal temperature variations: Observations and modeling, J. Geophys. Res., 93, 7466, 1988.

McCrea, I. W., Lester, M., Robinson, T. R., St.-Maurice, J.-P., Wade, N. M., and Jones, T. B.: Derivation of the ion temperature partition coefficient $\beta_{\|}$from the study of ion frictional heating events, J. Geophys. Res., 98, 15 701, 1993.

Nozawa, S. and Brekke, A.: A case study of the auroral E-region neutral wind on a quiet summer day: Comparison of the European Incoherent Scatter UHF radar for deriving the E-region wind, Radio Sci., 35, 845, 2000.

Rich, F. and Hairston, M.: Large-scale convection patterns observed by DMSP, J. Geophys. Res., 99, 3827, 1994.

Rino, C. L., Brekke, A., and Baron, M. J.: High-resolution auroral zone E-region neutral wind and current measurements by incoherent scatter radar, J. Geophys. Res., 82, 2295, 1977.

Schlegel, K. and St.-Maurice, J.-P.: Anomalous heating of the polar E-region by unstable plasma waves, 1. Observations, J. Geophys. Res., 86, 1447, 1981.

Schunk, R. W.: Mathematical structure of transport equations for multispecies flows, Rev. Geophys. Space Phys., 15, 429, 1977.

Schunk, R. W. and Nagy, A. F.: Ionospheres: Physics, Plasma Physics, and Chemistry, Cambridge University Press, Cambridge, 2000.
Schunk, R. W. and Walker, J. C. G.: Theoretical ion densities in the lower ionosphere, Planet. Space Sci., 21, 1975, 1973.

Smith, M. F. and Lockwood, M.: Earth's magnetospheric cusps, Rev. Geophysics., 34, 233, 1996.

St.-Maurice, J.-P. and Hanson, W. B.: Ion frictional heating at high latitudes and its possible use for an in situ determination of neutral thermospheric winds and temperatures, J. Geophys. Res., 87, 7580, 1982.

St.-Maurice, J.-P. and Schunk, R. W.: Auroral ion velocity distributions for a polarization collision model, Planet. Space Sci., 25, 243, 1977.

St.-Maurice, J.-P. and Schunk, R. W.: Ion velocity distributions in the high-latitude ionosphere, Rev. Geophys. Space Phys., 17, 99, 1979.

St.-Maurice, J.-P. and Kissack, R. S.: The role played by thermal feedback in heated Farley-Buneman waves at high latitudes, Ann. Geophysicae, 18, 532, 2000.

St.-Maurice, J.-P., Schlegel, K., and Banks, P. M.: Anomalous heating of the polar E-region by unstable plasma waves, 2. Theory, J. Geophys. Res., 86, 1453, 1981.

St.-Maurice, J.-P., Cussenot, C., and Kofman, W.: On the usefulness of E-region electron temperatures and lower F-region ion temperatures for the extraction of thermospheric parameters: a case study, Ann. Geophysicae, 17, 1182, 1999.

Thayer, J. P.: Height-resolved Joule heating rates in the highlatitude E-region and the influence of neutral winds, J. Geophys. Res., 103, 471, 1998.

Thayer, J. P. and Vickrey, J. F.: On the contribution of the thermospheric wind to high-latitude energetics, Geophys. Res. Lett., 19, 265, 1992.

Thayer, J. P., Vickrey, J. F., Heelis, R. A., and Gary, J. B.: Interpretation and modeling of the high-latitude electromagnetic energy flux, J. Geophys. Res., 100, 19715, 1995.

Venkat Raman, R. S., St.-Maurice, J. P., and Ong, R. S. B.: Incoherent scattering of radar waves in the auroral ionosphere, J. Geophys. Res., 86, 4751, 1981.

Wannberg, U. G., Wolf, I., Vanhainen, L. G., Koskeniemi, K., Röttger, J., Postila, M., Markannen, J., Jacobsen, R., Stenberg, A., Larsen, R., Eliassen, S., Heck, S., and Huuskonen, A.: The EISCAT Svalbard radar: a case study in modern incoherent scatter radar system design, Radio Sci., 32, 2283, 1997.

Williams, P. J. S., Jones, B., and Jones, G. O. L.: The measured relationship between electric field strength and electron temperature in the auroral E-region, J. Atmos. Terr. Phys., 54, 741, 1992.

Williams, P. J. S., Virdi, T. S., Jones, G. O. L., and Huuskonen, A.: A comparison of three methods of measuring tidal oscillations in the lower thermosphere using EISCAT common programs, J. Atmos. Terr. Phys., 56, 1347, 1994.

Winkler, E., St.-Maurice, J.-P., and Barakat, A. R.: Results from improved Monte Carlo calculations of auroral ion velocity distributions, J. Geophys. Res., 97, 8399, 1992. 